\title{
Effects of contact stress on patellarfemoral joint and quadriceps force in fixed and mobile-bearing medial unicompartmental knee arthroplasty
}

Hyuck Min Kwon ${ }^{1}$, Jin-Ah Lee ${ }^{2}$, Yong-Gon Koh ${ }^{3}$, Kwan Kyu Park ${ }^{1}$ and Kyoung-Tak Kang ${ }^{2 *}$

\begin{abstract}
Background: Unicompartmental knee arthroplasty (UKA) is an effective treatment for end-stage, symptomatic unicompartmental osteoarthritis of the knee joint. However, patellofemoral joint degeneration is a contraindication to medial UKA. Therefore, the objective of this study was to evaluate the biomechanical effect of medial UKA using fixed-bearing (FB) and mobile-bearing (MB) design prostheses on the patellofemoral joint.

Methods: A three-dimensional finite-element model of a normal knee joint was developed using medical image data. We performed statistical analysis for each model. The differences in contact stress on the patellofemoral joint and the quadriceps force between the FB and MB designs were evaluated under a deep-knee-bend condition.

Results: At an early flexion angle, the results of contact stress showed no significant difference between the FB and MB medial UKA models compared with the intact model. However, at high flexion angles, we observed a significant increase in contact stress with the FB models compared with the intact model. On the contrary, in the case of the MB models, we found no statistically significant increment compared with the intact model. A larger quadriceps force was needed to produce an identical flexion angle for both the FB and MB UKA designs than for the intact model. At high flexion angles, a significant increase quadriceps force whit the FB model compared with the intact model.

Conclusions: Our results indicate that with medial UKA, the contact stress increased and greater quadriceps force was applied to the patellofemoral joint. However, performing UKA on a patellofemoral joint with osteoarthritis should not be difficult, unless anterior knee pain is present, because the increase in contact stress is negligible.
\end{abstract}

Keywords: Finite-element method, Unicompartmental knee arthroplasty, Patellofemoral joint

\footnotetext{
*Correspondence: tagi1024@gmail.com

Hyuck Min Kwon and Jin-Ah Lee contributed equally to this work and should be considered co-first authors.

${ }^{2}$ Department of Mechanical Engineering, Yonsei University, 50 Yonsei-ro, Seodaemun-gu, Seoul 03722, Republic of Korea

Full list of author information is available at the end of the article
}

C C The Author(s). 2020 Open Access This article is licensed under a Creative Commons Attribution 4.0 International License, which permits use, sharing, adaptation, distribution and reproduction in any medium or format, as long as you give appropriate credit to the original author(s) and the source, provide a link to the Creative Commons licence, and indicate if changes were made. The images or other third party material in this article are included in the article's Creative Commons licence, unless indicated otherwise in a credit line to the material. If material is not included in the article's Creative Commons licence and your intended use is not permitted by statutory regulation or exceeds the permitted use, you will need to obtain permission directly from the copyright holder. To view a copy of this licence, visit http://creativecommons.org/licenses/by/4.0/ The Creative Commons Public Domain Dedication waiver (http://creativecommons.org/publicdomain/zero/1.0/) applies to the data made available in this article, unless otherwise stated in a credit line to the data. 


\section{Background}

Unicompartmental knee arthroplasty (UKA) is a surgical treatment alternative to total knee arthroplasty for isolated medial compartmental arthritis of the knee joint. The benefits of UKA include fewer complications, faster recovery, improved functional outcomes, and costeffectiveness [1-4]. Therefore, medial UKA had been increasingly used for the treatment of medial compartmental osteoarthritis (OA) over the past two decades [5]. Historically, patellofemoral (PF) joint degeneration, and more specifically, advanced lateral PF joint facet degeneration, along with anterior knee pain, has been considered as an exclusion criterion for medial UKA [6, 7]. However, PF joint degeneration has been reported recently to have no influence on the clinical outcomes after UKA [8, 9]. In addition, whether preexisting PF joint degeneration is a contraindication to UKA is controversial. Thein et al. recently performed a study to determine the effect of medial fixed-bearing (FB) UKA on postoperative PF joint congruence and analyzed the effect of preoperative PF joint degeneration on the clinical outcome [10]. No correlation was observed between preoperative PF joint congruence or degeneration severity and the Western Ontario and McMaster Universities Osteoarthritis Index (WOMAC) scores at 2-year followup [10]. Preoperative PF joint congruence and degenerative changes do not affect the clinical outcomes after UKA [10]. However, multiple studies that used the Oxford knee system indicated that neither preoperative anterior knee pain nor moderate radiological PF osteoarthritic changes affected the long-term clinical outcomes and survivorship of patients after mobilebearing (MB) UKA $[9,11,12]$. One study suggested that MB UKA provides better restoration of normal knee kinematics, which theoretically translates to better patellar tracking and long-term outcomes [13]. Although several studies have revealed no significant differences in clinical outcomes and complication rates between the FB and MB UKA designs, the mode of failure often differs [14]. In addition, research on the biomechanical effect of medial UKA on the PF joint is lacking. The biomechanical effect on the PF joint can be investigated by performing a finite-element (FE) analysis to evaluate the contact stress and quadriceps force after medial UKA [15]. Accurate in silico evaluations of knee joint replacements are useful for clinical assessment [15].

Therefore, the objective of this study was to evaluate the biomechanical effects of medial UKA using FB and $\mathrm{MB}$ design prostheses on the PF joint. The differences in contact stress on the PF joint and quadriceps force between the $\mathrm{FB}$ and $\mathrm{MB}$ designs were evaluated under a deep-knee-bend condition. We hypothesized that applying medial UKA would not be difficult even with OA of the PF joint (unless accompanied by anterior knee pain) because the differences in biomechanical effect on the PF joint are negligible between the UKA and normal knee joint models.

\section{Methods \\ Normal knee joint model}

In this study, an existing three-dimensional non-linear FE model of the knee joint based on data from four male subjects (subject 1: age, 36 years; height, $178 \mathrm{~cm}$; mass, $75 \mathrm{~kg}$; subject 2: age, 34 years; height, $173 \mathrm{~cm}$; mass, 83 kg; subject 3: age, 32 years; height, $182 \mathrm{~cm}$; mass, $79 \mathrm{~kg}$; subject 4: age, 34 years; height, $173 \mathrm{~cm}$; mass, $71 \mathrm{~kg}$ ) and one female subject (subject 5: age, 26 years; height, 163 $\mathrm{cm}$; mass, $65 \mathrm{~kg}$ ) was used. The FE model was developed using computed tomography and magnetic resonance imaging data with a slice thikness of $0.1 \mathrm{~mm}$ and 0.4 mm slice, respectively $[16,17]$ and included the bony structures of the knee joint and the soft tissues of the PF and tibiofemoral (TF) joint anatomies. The articular cartilage and menisci were defined as isotropic linearly elastic materials and transversely isotropic and linearly elastic materials, respectively [18]. The material properties of the articular cartilage and menisci are presented in Table 1.

All the ligaments were modeled with nonlinear and tension-only spring elements $[19,20]$. Mesh convergence tests were performed to complete the simulation. Convergence was obtained if the relative change between two adjacent meshes was $<5 \%$. The average element sizes were $0.8 \mathrm{~mm}$ for the cartilage and menisci, respectively. The details of the meshes used in the FE model were described in Table 2. The interfaces between the cartilage and bones were modeled to be fully bonded. Contact was applied between the femoral cartilage and meniscus, meniscus and tibial cartilage, and femoral cartilage and tibial cartilage for both the medial and lateral sides [16].

\section{Medial UKA model}

A FB UKA prosthesis (Zimmer, Inc., Warsaw, IN, USA) and a MB UKA prosthesis of the Oxford knee system (Biomet, Warsaw, IN) were virtually implanted in the medial compartment of the normal knee joint model. (Fig. 1) The bone models were imported and appropriately positioned, trimmed, and meshed with rigid elements according to the surgical techniques [16]. The tibial component was defined as a square $\left(0^{\circ}\right)$ inclination in the coronal plane, with a $5^{\circ}$ posterior slope. The rotating axis was defined as a line parallel to the lateral edge of the tibial component passing through the center of the femoral component peg. A femoral component distal cut perpendicular to the mechanical axis of the femur and parallel to the tibial cut was reproduced. The height of the PE insert was identical to the anatomy in a sagittal 
Table 1 Material properties of the articular cartilage and menisci

\begin{tabular}{lll}
\hline Cartilage & Linearly elastic, & $E=15 \mathrm{MPa}$ \\
& isotropic & $v=0.475$ \\
Menisci & Linearly elastic, & $E_{\theta}=150 \mathrm{MPa}, E_{r}=E_{z}=20 \mathrm{MPa}$ \\
& transversely isotropic & $v_{r z}=0.2, v_{r \theta}=v_{z \theta}=0.3, G_{r \theta}=G_{z \theta}=57.7 \mathrm{MPa}$ \\
\hline
\end{tabular}

plane aligned with the mechanical axis of the tibia and positioned at the medial edge of the tibia. The materials used for the femoral component, tibial insert, tibial baseplate, and bone cement were cobalt chromium molybdenum alloy, ultrahigh-molecular-weight polyethylene, titanium alloy, and polymethyl methacrylate, respectively (Table 3) [17, 21, 22].

The femoral component and tibial insert were in contact with a coefficient of friction of 0.04 [21]. The FE simulation involved two types of loading conditions corresponding to the loads used in the model validation experiment and to predictions of loading scenarios in daily activities. An axial loading of $1150 \mathrm{~N}$ was applied to the model to evaluate the contact stresses and compare them with those reported in previous studies [23] (Fig. 2). The second loading condition corresponded to a deep knee bend, and squat loading was applied to evaluate the knee joint mechanics. A computational analysis was performed using an anteroposterior force applied to the femur that was based on the compressive load applied to the hip with constrained femoral internal-external (IE) rotation, free medial-lateral translation, and knee flexion, for a combination of vertical hip and quadriceps loads. Therefore, a 6degrees-of-freedom (DOF) TF joint was developed [24, 25]. A proportional-integral-derivative controller was incorporated into the computational model to control the quadriceps in a manner similar to that in previous experiments [26]. A control system was used to calculate the instantaneous displacement of the quadricep muscles to match the target flexion profile used in the experiment. Furthermore, IE and varus-valgus torques were applied to the tibia, while the remaining tibial DOF were constrained $[24,25]$.

Table 2 Details of meshes used in the FE model

\begin{tabular}{llll}
\hline Set & Nomal knee & FB UKA & MB UKA \\
\hline Femur bone (Quad) & 18,817 & 17,948 & 17,899 \\
Tibia bone (Quad) & 13,286 & 12,303 & 12,289 \\
Fibula bone (Quad) & 5456 & 5456 & 5456 \\
Patella bone (Hexa) & 1411 & 1411 & 1411 \\
Femur cartilage (Hexa) & 9629 & 4586 & 4586 \\
Meniscus (Hexa) & 2978 & 1475 & 1475 \\
Femoral componennt (Hexa) & - & 7335 & 7523 \\
PE insert (Hexa) & - & 2872 & 3125 \\
Tibia tray (Hexa) & - & 2421 & 3094 \\
Total & 51,577 & 55,807 & 56,858 \\
\hline
\end{tabular}

The FE models were analyzed using Abaqus version 6.11 software (Simulia, Providence, RI, USA). The contact stress and quadriceps force on the PF joint were evaluated for the FB and MB medial UKA designs.

\section{Statistical analyses}

We performed the test at 11 time points $(0.0$ to 1.0 phases) for single cycles of deep-knee-bend loading conditions. To assess the two models, FB and MB, the condition of each model was compared with that of the normal knee in a pairwise manner by using nonparametric repeated-measures Friedman tests at each phase of the cycle. In this study, we used Wilcoxon rank test with Holm correction for post hoc comparisons to control the familywise error rate for the tests conducted within each phase of the cycle. Statistical analyses were performed using SPSS version 20.0.0 for Windows (SPSS Inc., Chicago, IL, USA). Statistical significance was set at $P<.05$.

\section{Results}

The results of the five subject-specific FE models were compared with previous results of the same model for model validation [23]. The mean contact stresses on the medial and lateral menisci in the present and previous studies are presented in Table 4.

The minor differences may be due to the variations in geometry, such as the thicknesses of the cartilage and meniscus, between the studies. However, the consistency between the results confirms the ability of the FE model to produce reasonable results [23]. Figure 3 shows the contact stresses on the PF joint with the $\mathrm{FB}$ and $\mathrm{MB}$ medial UKA designs under the deep-knee-bend condition. No significant difference in contact stress on the PF joint was observed between the FB and MB medial UKA models and the intact model at an early flexion angle. At a larger flexion angle, the contact stress showed a significant increase of $7 \%$ (on average), which is a small but significant increase, for the FB model compared with the intact model. For the MB models, we observed an increase of $4 \%$ (on average) in contact stress. However, we found no statistically significant increment.

The quadriceps forces exerted on the PF joint with the FB and MB medial UKA designs under the deep-kneebend condition are shown in Fig. 4. A larger quadriceps force was needed to produce an identical flexion angle for both the FB and MB UKA designs than for the intact model. The quadriceps force rapidly increased the 


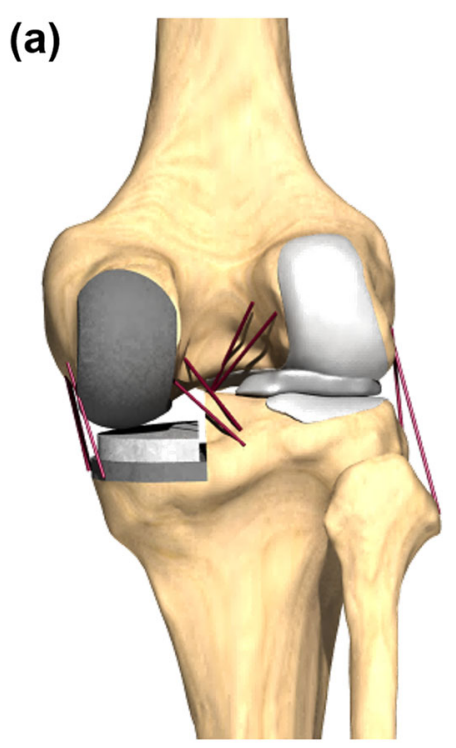

(b)

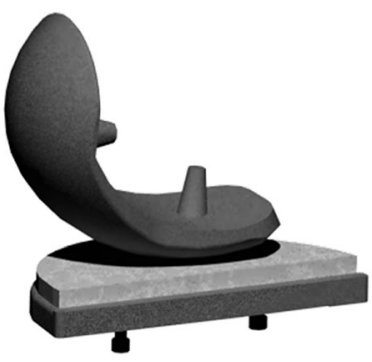

(c)

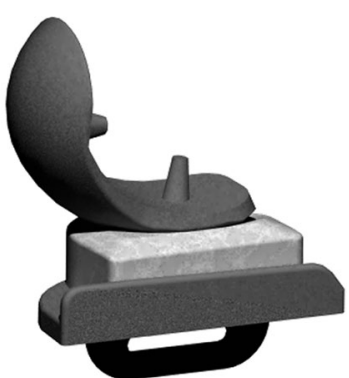

Fig. 1 FE model used in this study for a UKA model, b FB UKA componenet design, and c MB UKA componenet design

flexion of the knee joint in all the models. On average, the maximum quadriceps force significantly ranged from $2710 \mathrm{~N}$ for the MB UKA design to $2830 \mathrm{~N}$ for the FB UKA design. At a mid-flexion angle, the quadriceps forces were smaller for the FB and MB UKA designs than for the intact model. In addition, a lower quadriceps force was needed to produce identical flexion angles with the MB UKA design than with the FB UKA design. And at high flexion angles, a significant increase quadriceps force whit the FB model compared with the intact model. The FB and MB UKA designs required $12 \%$ and $8 \%$ (on average) more quadriceps force, respectively, than the intact model.

\section{Discussion}

The most important finding of this study was that the contact stress on the PF joint increased less with the MB UKA design than with the FB UKA design; however, no significant difference in contact stress on the PF joint was found between the medial UKA and intact knee joints. The quadriceps force needed to produce the same flexion angle with the MB UKA design was lower than that with the FB UKA design. UKA can be performed

Table 3 Material properties of implant

\begin{tabular}{lll}
\hline & Young's modulus (MPa) & Poisson's ratio \\
\hline CoCr alloy & 220,000 & 0.30 \\
UHMWPE & 685 & 0.47 \\
Ti6Al4V alloy & 110,000 & 0.30 \\
PMMA & 1,940 & 0.4 \\
\hline
\end{tabular}

with either an $\mathrm{FB}$ or $\mathrm{MB}$ design. In a prospective study that involved 48 patients, who were randomly assigned to either $\mathrm{FB}$ or MB UKA prostheses, $\mathrm{Li}$ et al. observed better knee kinematics and a lower incidence of radiolucency with the MB design, but the Knee Society, WOMAC, and SF-36 scores were equivalent between the two designs [27]. In another study, the range of motion, limb alignment, patient-reported outcomes, incidence of aseptic loosening, and reoperation rate were identical between the FB and MB UKA designs [28]. However, the time to reoperation and failure mode differed. Early failure due to bearing dislocation occurred with the $M B$ design, whereas late failure due to polyethylene wear occurred with the FB design. A previous study indicated that during a $\geq 15$-year follow-up period, some type of revision arthroplasty was required for 12 (15\%) of 77 knees in the case of FB UKA (MillerGalante; Zimmer) and for 10 (12\%) of 79 knees in the case of MB UKA (Oxford; Biomet) [29]. No significant differences were observed in the number of knees with progressive lateral $\mathrm{OA}$ that required revision arthroplasty between the FB and MB UKA designs [29]. Thus, many arguments have emerged regarding the biomechanical issues of the FB and MB UKA designs. In previous studies on the progression of $\mathrm{OA}$ after UKA, the radiological assessment was neither blinded nor randomized [27].

The advantage of $\mathrm{FE}$ analysis is that the impact of the UKA design can be determined without external variables [30]. Most in vitro biomechanical studies have involved evaluations using aged cadaveric subjects with loosening between the specimen and the 

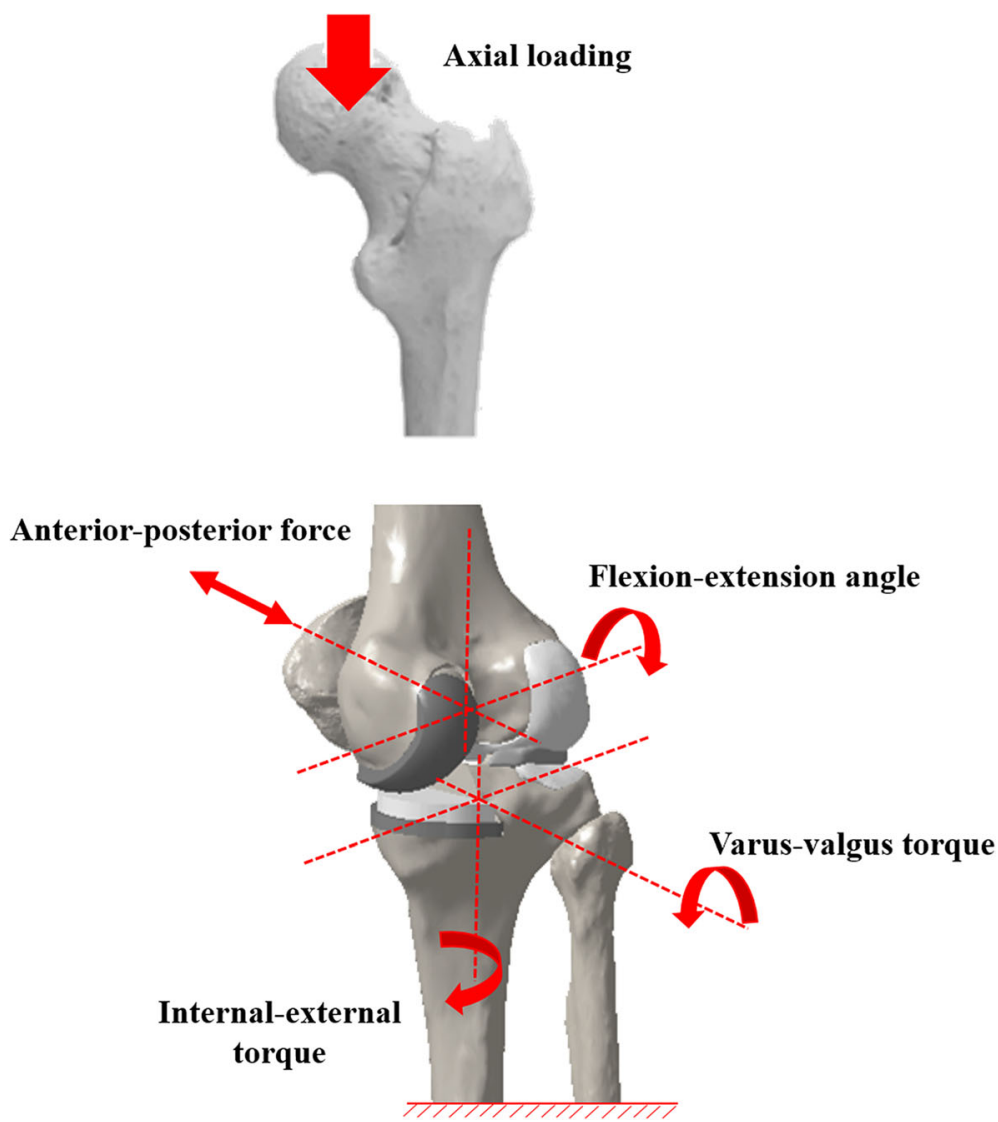

Fig. 2 Loading condition of the UKA FE model

device, and tissue attenuation, which can occur owing to the successive loading in mechanical testing [26]. An intact joint model was the foundation of this study and involved FEM validation steps. The results exhibited good agreement with those of previous computational studies [23, 31]. Therefore, the UKA models used in the present study and related analyses are considered reliable.

Kozinn and Scott proposed that UKA should not be offered to patients with PF joint arthritis for optimal results [32]. This sparked a contentious debate on PF joint disease because other authors demonstrated only a weak correlation between PF degenerative changes and anterior knee pain $[11,33]$.

In addition, owing to the differences in the design and biomechanics of the FB UKA model, damage to the PF joint has traditionally been a contraindication. Lim et al. recently showed that the presence of significant preoperative radiological PF disease does not affect longterm implant success, and patients had excellent postoperative functional outcomes for 10 years [34]. In the present study, the MB UKA design produced a smaller increase in contact stress on the PF joint than the intact joint and FB UKA design models. The results of previous studies on MB UKA indicated that the presence of PF degeneration does not compromise clinical outcomes because the implant is believed to be more patella friendly owing to better kinematics, which supports our results [34, 35]. Moreover, although the contact stress on the PF joint increased with both the $\mathrm{FB}$ and $\mathrm{MB}$ UKA designs, the increase was not statistically significant. Biomechanical studies have indicated that the progression of arthritis of the PF joint typically does not necessitate revision.

Table 4 Comparison of the average contact stresses on the menisci for the validation of the model under an axial loading condition

\begin{tabular}{llll}
\hline & Previous study [23] & Present study & Standard deviation \\
\hline Medial meniscus (MPa) & 2.9 & 3.1 & 0.4 \\
Lateral meniscus (MPa) & 1.4 & 1.5 & 0.6 \\
\hline
\end{tabular}




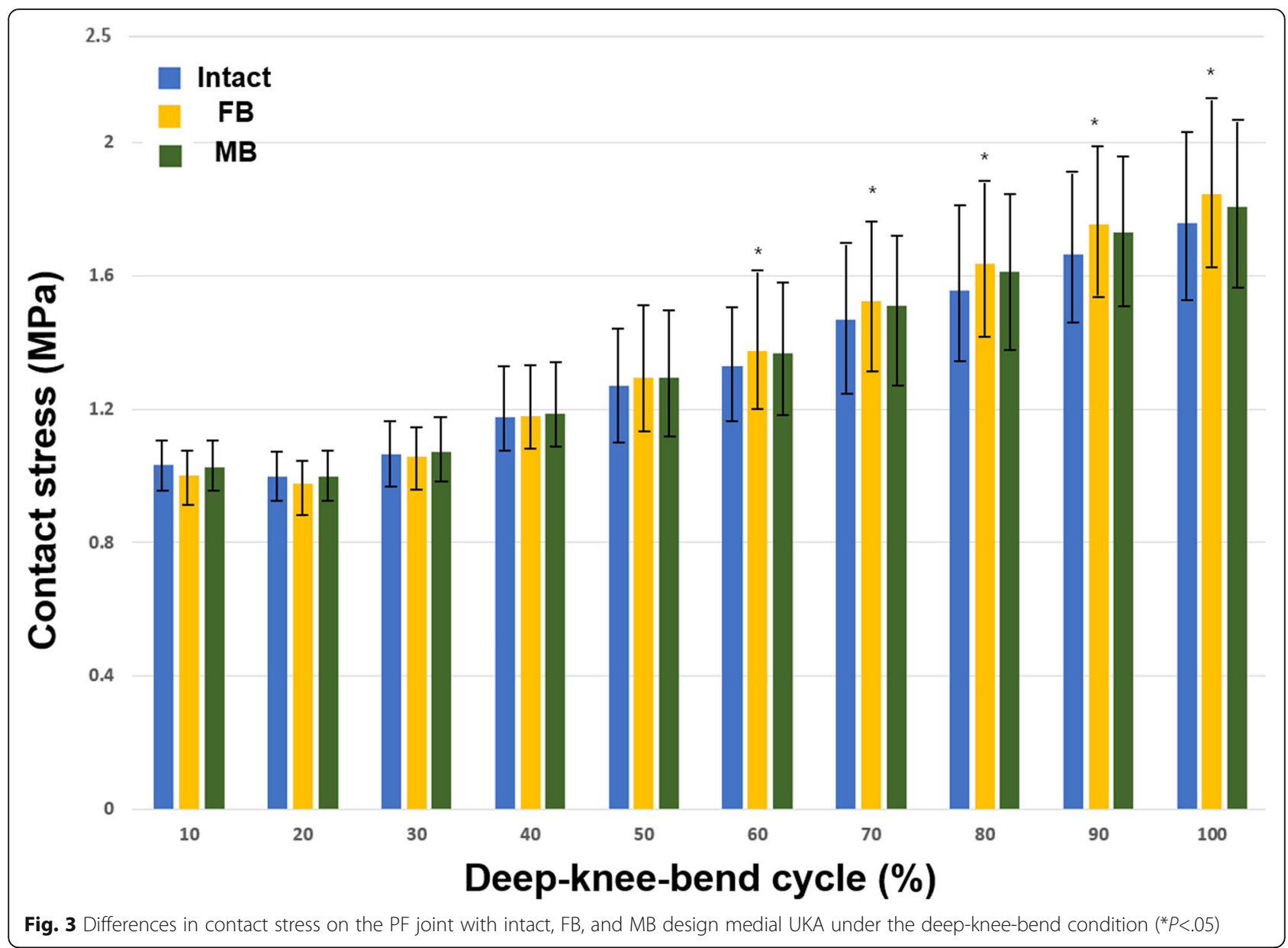

The quadriceps force needed to produce a squatting motion was greater for the FB design than for the MB design (by as much as $120 \mathrm{~N}$ for knee flexion angles > $\left.100^{\circ}\right)$. Thus, increased quadriceps strength leads to improved functional performance [36]. As patients who have undergone $\mathrm{OA}$ and knee arthroplasty experience significant quadriceps weakness, the FB UKA design, which increases the required quadriceps force, can result

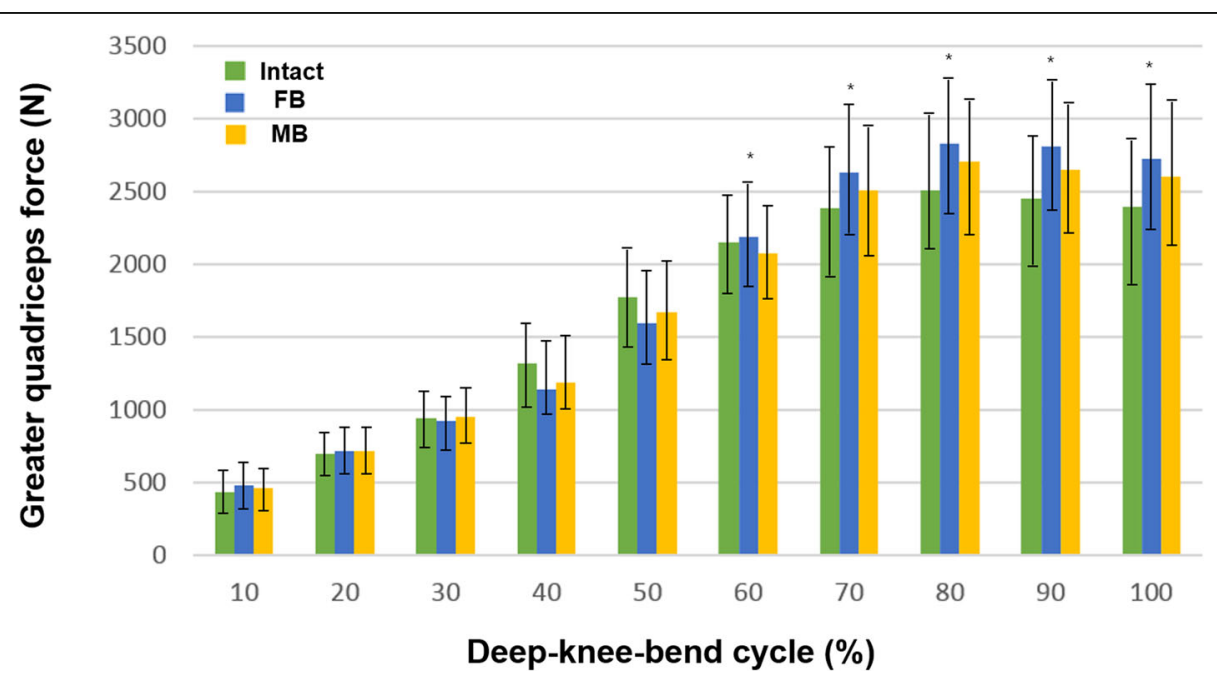

Fig. 4 Differences in the quadriceps muscle force for intact, FB, and MB tibial insert materials under the deep-knee-bend condition ( ${ }^{*} P<.05$ ) 
in more difficulty for patients to walk, kneel, or perform a deep knee bend [37]. This agrees with the results of a previous in vitro study in which a UKA model required less quadriceps force at a mid-flexion angle than an intact model [27].

From a biomechanical viewpoint, our results indicate that the risk of progressive OA of the PF joint can be reduced with the MB UKA design because it preserves the normal biomechanical effect, in contrast to the FB UKA design. In addition, the MB UKA design requires a lower quadriceps force and makes it easier for recipients to kneel, squat, or rise from a chair.

The three strengths of our study should be highlighted. First, a well-validated setup that accounted for numerous previous results was used. Second, in contrast to previous UKA studies, the present study included the tibia, femur, and related soft tissues in the FE model. Third, in contrast to the current biomechanical UKA models, the model used in this study included the deep-knee-bend and squat loading conditions, rather than the simple vertical static loading condition.

Despite these strengths, this study had certain limitations. First, the results did not predict clinical results or patient satisfaction. Second, the computational model was developed using data from four male subjects and one female subject. Using data from subjects of various ages would improve the validity of the results, as it would increase the diversity of the knee joint geometry. However, in this study, our objective was to evaluate the biomechanical effect of UKA in young individuals. Third, the bony structures were assumed to be rigid. In reality, the bone is composed of cortical and cancellous tissues. However, the main purpose of the study was not to evaluate the effects of different prostheses on bone. In addition, this assumption had a minimal influence on the results of the study because the bone stiffness exceeds that of the relevant soft tissues [23]. Finally, the simulation only involved a deep knee bend; thus, simulations involving rising from or sitting on chairs, climbing/descending stairs, and squatting should be performed in future investigations.

In conclusion, this study provides biomechanical evidence that degenerative changes in the PF joint should not be considered an absolute contraindication to treatment with medial UKA. In addition, UKA is not problematic even in PF joints with OA, unless accompanied by anterior knee pain, because no significant difference in contact stress was observed.

\footnotetext{
Abbreviations

UKA: Unicompartmental knee arthroplasty; OA: Osteoarthritis; PF: Patellofemoral; FB: Fixed-bearing; MB: Mobile-bearing; TF: Tibiofemoral; IE: Internal-external; DOF: Degree of freedom
}

\section{Authors' contributions}

HMK designed the study and drafted the paper. JAL developed the threedimensional model. YGK evaluated the FEA results. KKP validated the data.
KTK supervised the study and analyzed the data. All authors read and approved the final manuscript.

\section{Funding}

There is no funding source.

Availability of data and materials

Not applicable.

Ethics approval and consent to participate

Approval was not required, as neither human participants nor animals were involved in this study.

Consent for publication

Not applicable.

\section{Competing interests}

The authors declare that they have no competing interests.

\section{Author details}

${ }^{1}$ Department of Orthopedic Surgery, Yonsei University College of Medicine, 50-1 Yonsei-ro, Seodaemun-gu, Seoul 03722, Republic of Korea. ${ }^{2}$ Department of Mechanical Engineering, Yonsei University, 50 Yonsei-ro, Seodaemun-gu, Seoul 03722, Republic of Korea. ${ }^{3}$ Joint Reconstruction Center, Department of Orthopaedic Surgery, Yonsei Sarang Hospital, 10 Hyoryeong-ro, Seocho-gu, Seoul 06698, Republic of Korea.

Received: 13 February 2020 Accepted: 28 October 2020

Published online: 10 November 2020

\section{References}

1. Siman H, Kamath AF, Carrillo N, Harmsen WS, Pagnano MW, Sierra RJ. Unicompartmental Knee Arthroplasty vs Total Knee Arthroplasty for Medial Compartment Arthritis in Patients Older Than 75 Years: Comparable Reoperation, Revision, and Complication Rates. J Arthroplasty. 2017;32(6): 1792-7.

2. Liddle AD, Judge A, Pandit H, Murray DW. Adverse outcomes after total and unicompartmental knee replacement in 101,330 matched patients: a study of data from the National Joint Registry for England and Wales. Lancet (London, England). 2014;384(9952):1437-45.

3. Kim MS, Koh IJ, Choi YJ, Lee JY, In Y. Differences in Patient-Reported Outcomes Between Unicompartmental and Total Knee Arthroplasties: A Propensity Score-Matched Analysis. J Arthroplasty. 2017:32(5):1453-9.

4. Shankar S, Tetreault MW, Jegier BJ, Andersson GB, Della Valle CJ. A cost comparison of unicompartmental and total knee arthroplasty. The Knee. 2016;23(6):1016-9.

5. Borus T, Thornhill T. Unicompartmental knee arthroplasty. J Am Acad Orthop Surg. 2008;16(1):9-18

6. Foran JR, Brown NM, Della Valle CJ, Berger RA, Galante JO. Long-term survivorship and failure modes of unicompartmental knee arthroplasty. Clin Orthop Relat Res. 2013;471(1):102-8.

7. Kozinn SC, Scott RD. Surgical treatment of unicompartmental degenerative arthritis of the knee. Rheum Dis Clin North Am. 1988;14(3):545-64.

8. Berend KR, Lombardi AV Jr. Liberal indications for minimally invasive oxford unicondylar arthroplasty provide rapid functional recovery and pain relief. Surg Technol Int. 2007;16:193-7.

9. Beard DJ, Pandit H, Ostlere S, Jenkins C, Dodd CA, Murray DW. Pre-operative clinical and radiological assessment of the patellofemoral joint in unicompartmental knee replacement and its influence on outcome. J Bone Joint Surg Br. 2007;89(12):1602-7.

10. Thein R, Zuiderbaan HA, Khamaisy S, Nawabi DH, Poultsides LA, Pearle AD. Medial unicondylar knee arthroplasty improves patellofemoral congruence: a possible mechanistic explanation for poor association between patellofemoral degeneration and clinical outcome. J Arthroplasty. 2015; 30(11):1917-22

11. Hamilton TW, Pandit HG, Maurer DG, Ostlere SJ, Jenkins C, Mellon SJ, et al. Anterior knee pain and evidence of osteoarthritis of the patellofemoral joint should not be considered contraindications to mobile-bearing unicompartmental knee arthroplasty: a 15-year follow-up. Bone Joint J. 2017;99-b(5):632-9. 
12. Kim KT, Lee S, Lee JS, Kang MS, Koo KH. Long-term clinical results of unicompartmental knee arthroplasty in patients younger than 60 years of age: minimum 10-year follow-up. Knee Surg Relat Res. 2018;30(1):28-33.

13. Argenson JN, Parratte S. The unicompartmental knee: design and technical considerations in minimizing wear. Clin Orthop Relat Res. 2006;452:137-42.

14. Gleeson RE, Evans R, Ackroyd CE, Webb J, Newman JH. Fixed or mobile bearing unicompartmental knee replacement? A comparative cohort study. Knee. 2004;11(5):379-84.

15. Kwon OR, Kang KT, Son J, Suh DS, Baek C, Koh YG. Importance of joint line preservation in unicompartmental knee arthroplasty: Finite element analysis. J Orthop Res. 2017;35(2):347-52.

16. Park KK, Koh YG, Park KM, Park JH, Kang KT. Biomechanical effect with respect to the sagittal positioning of the femoral component in unicompartmental knee arthroplasty. Bio-med Mater Eng. 2019:30(2):171-82.

17. Koh YG, Lee JA, Lee HY, Chun HJ, Kim HJ, Kang KT. Anatomy-mimetic design preserves natural kinematics of knee joint in patient-specific mobilebearing unicompartmental knee arthroplasty. Knee Surg Sports Traumatol Arthrosc. 2019;28(5):1465-72.

18. Haut Donahue TL, Hull M, Rashid MM, Jacobs CR. How the stiffness of meniscal attachments and meniscal material properties affect tibio-femora contact pressure computed using a validated finite element model of the human knee joint. J Biomech. 2003;36(1):19-34.

19. Mesfar W, Shirazi-Adl A. Biomechanics of the knee joint in flexion under various quadriceps forces. The Knee. 2005;12(6):424-34.

20. Takeda Y, Xerogeanes JW, Livesay GA, Fu FH, Woo SL. Biomechanical function of the human anterior cruciate ligament. Arthroscopy. 1994;10(2):140-7.

21. Godest AC, Beaugonin M, Haug E, Taylor M, Gregson PJ. Simulation of a knee joint replacement during a gait cycle using explicit finite element analysis. J Biomech. 2002;35(2):267-75.

22. Inoue S, Akagi M, Asada S, Mori S, Zaima H, Hashida M. The Valgus Inclination of the Tibial Component Increases the Risk of Medial Tibial Condylar Fractures in Unicompartmental Knee Arthroplasty. J Arthroplasty. 2016;31(9):2025-30.

23. Pena E, Calvo B, Martinez MA, Palanca D, Doblare M. Why lateral meniscectomy is more dangerous than medial meniscectomy. A finite element study. J Orthop Res. 2006:24(5):1001-10.

24. Kutzner I, Heinlein B, Graichen F, Bender A, Rohlmann A, Halder A, et al. Loading of the knee joint during activities of daily living measured in vivo in five subjects. J Biomech. 2010;43(11):2164-73.

25. Halloran JP, Clary CW, Maletsky LP, Taylor M, Petrella AJ, Rullkoetter PJ. Verification of predicted knee replacement kinematics during simulated gait in the Kansas knee simulator. J Biomech Eng. 2010;132(8):081010.

26. Kang KT, Koh YG, Son J, Kim SJ, Choi S, Jung M, et al. Finite element analysis of the biomechanical effects of 3 posterolateral corner reconstruction techniques for the knee joint. J Arthroscopy. 2017;33(8):1537-50.

27. Heyse TJ, El-Zayat BF, De Corte R, Scheys L, Chevalier Y, Fuchs-Winkelmann $S$, et al. Biomechanics of medial unicondylar in combination with patellofemoral knee arthroplasty. Knee. 2014;21(Suppl 1):S3-9.

28. Cheng T, Chen D, Zhu C, Pan X, Mao X, Guo Y, et al. Fixed- versus mobilebearing unicondylar knee arthroplasty: are failure modes different? Knee Surg Sports Traumatol Arthrosc. 2013;21(11):2433-41.

29. Parratte S, Pauly $V$, Aubaniac JM, Argenson JN. No long-term difference between fixed and mobile medial unicompartmental arthroplasty. Clin Orthopaed Relat Res. 2012;470(1):61-8.

30. Kang KT, Koh YG, Son JH, Kwon OR, Lee JS, Kwon SK. Influence of increased posterior tibial slope in total knee arthroplasty on knee joint biomechanics: a computational simulation study. J Arthroplasty. 2018:33(2):572-9.

31. Kang KT, Kim SH, Son J, Lee YH, Chun HJ. Computational model-based probabilistic analysis of in vivo material properties for ligament stiffness using the laxity test and computed tomography. J Mater Sci Mater Med. 2016;27(12):183

32. Kozinn SC, Scott R. Unicondylar knee arthroplasty. J Bone Joint Surg Am. 1989;71(1):145-50.

33. Song EK, Park JK, Park CH, Kim MC, Agrawal PR, Seon JK. No difference in anterior knee pain after medial unicompartmental knee arthroplasty in patients with or without patellofemoral osteoarthritis. Knee Surg, Sports Traumatol Arthrosc. 2016;24(1):208-13.

34. Lim JW, Chen JY, Chong HC, Pang HN, Tay DKJ, Chia SL, et al. Pre-existing patellofemoral disease does not affect 10-year survivorship in fixed bearing unicompartmental knee arthroplasty. Knee Surg Sports Traumatol arthrosc. 2019;27(6):2030-6.
35. Argenson JN, O'Connor JJ. Polyethylene wear in meniscal knee replacement. A one to nine-year retrieval analysis of the Oxford knee. J Bone Joint Surg Br. 1992;74(2):228-32.

36. Hurley MV, Scott DL. Improvements in quadriceps sensorimotor function and disability of patients with knee osteoarthritis following a clinically practicable exercise regime. Br J Rheumatol. 1998;37(11):1181-7.

37. Mizner RL, Petterson SC, Stevens JE, Vandenborne K, Snyder-Mackler L. Early quadriceps strength loss after total knee arthroplasty. The contributions of muscle atrophy and failure of voluntary muscle activation. J Bone Joint Surg Am. 2005;87(5):1047-53.

\section{Publisher's Note}

Springer Nature remains neutral with regard to jurisdictional claims in published maps and institutional affiliations.
Ready to submit your research? Choose BMC and benefit from:

- fast, convenient online submission

- thorough peer review by experienced researchers in your field

- rapid publication on acceptance

- support for research data, including large and complex data types

- gold Open Access which fosters wider collaboration and increased citations

- maximum visibility for your research: over $100 \mathrm{M}$ website views per year

At BMC, research is always in progress.

Learn more biomedcentral.com/submissions 